TITLE:

\title{
ORIGIN AND DISPERSAL OF MYTILUS EDULIS IN JAPAN DEDUCED FROM ITS PRESENT STATUS OF COPEPOD PARASITISM
}

\section{$\operatorname{AUTHOR}(\mathrm{S}):$}

Ho, Ju-shey

\section{CITATION:}

Ho, Ju-shey. ORIGIN AND DISPERSAL OF MYTILUS EDULIS IN JAPAN DEDUCED FROM ITS PRESENT STATUS OF COPEPOD PARASITISM. PUBLICATIONS OF THE SETO MARINE BIOLOGICAL LABORATORY 1980, 25(5-6): 293-313

\section{ISSUE DATE:}

1980-11-15

URL:

http://hdl.handle.net/2433/176009

RIGHT: 


\title{
ORIGIN AND DISPERSAL OF MYTILUS EDULIS IN JAPAN DEDUCED FROM ITS PRESENT STATUS OF COPEPOD PARASITISM
}

\author{
JU-SHEY HO \\ Department of Biology, California State University, Long Beach, California, 90840, U.S.A.
}

With Text-figures $1-8$ and Table 1

\section{Introduction}

Japan is one of the few countries in the world where the marine copepod parasite fauna is relatively well known, with nearly 300 species being recorded from both fishes and invertebrates. However, an analysis of their geographical distribution indicates that a disproportionately large number of them, 251 species (about $84 \%$ ), were recorded from the warm-temperate waters of the Pacific coast south of Cape Inubo and only 28 species (about $9 \%$ ) are known from the Sea of Japan. In order to correct this artificial imbalance in the distribution of copepod parasites, I spent four months (from August to November) in 1978 to collect the copepod parasites of marine animals in the cold-temperate waters of the Sea of Japan. During which time, I had opportunity to examine 109 species of fishes and 86 species of invertebrates, and recovered copepod parasites from 50 species of the former and 35 species of the latter.

While collecting on Sado Island, I examined for their copepod parasites three species of marine mussels (Mytilidae), namely, Mytilus edulis Linnaeus, $M$. corscus Gould, and Septifer virgatus (Weigmann). In addition, M. edulis on Noto Peninsula was also examined. In order to make a comparison of parasite fauna between the mytilids of the Sea of Japan and that of the Pacific coast, specimens of S. virgatus from Sirahama, Wakayama Prefecture were also examined. Examination of these mussels has resulted in a discovery of four species of copepod parasites with two of them being new to science.

In southern California, like in Japan, there live also two species of Mytilus. A species of parasitic copepod, Pseudomyicola spinosus (Raffaele \& Monticelli), is so common and abundant in these mussels in southern California that both the host and the parasite have become some of the regular laboratory materials for teaching in the class of marine invertebrate zoology. I have checked intermittently in the past nine years the incidence of copepod parasites in the mussels that were brought into the laboratory for the class use. A critical analysis of these data together with the ones collected from Japan has revealed that the present status of parasite infestation in the blue mussel ( $M$. edulis) indicates a very recent entry of this mussel into

Publ. Seto Mar. Biol. Lab., XXV (5/6), 293-313, 1980. (Article 18) 
Japan. The present report deals with the account on this parasites' implication as well as reporting the four species of copepod parasites recently discovered from the Japanese mussels.

\section{Parasites of Immigrant Host}

Parasites occur in the nature only in the region where there are suitable hosts. Theoretically, if a species of host was emigrated (either by natural dispersal or artificial means) to a different and separated region and survived, the accompanying parasites would be either kept by or lost from this emigrant host in the new habitat (Manter, 1967).

All parasites live in two kinds of environment (Dogiel, 1961). When parasites emigrate with their host to a new region, the parasite's microenvironment (host's biological conditions) remains unchanged (for some time), whereas their macroenvironment (the one in which both the host and its parasites live) confronts them with various degrees of alteration, especially in the case of parasites with indirect life cycle that requires intermediate host(s). It is this immediate change in the macroenvironmental conditions that determines the fate of the immigrant parasites. Those survived are generally the kinds that possess a direct life cycle with a low host specificity (generalized host requirements). Thus, we find frequently that an ectoparasite with generalized host requirements can become a cosmopolitan species if some of its hosts have a world-side distribution. For example, Lernaea cyprinacea Linnaeus is a copepod parasite with low host specificity to cyprinid fish; since two of its hosts, carp and goldfish, have been artificially dispersed to all continents, L. cyprinacea has become the most common cosmopolitan copepod parasites.

The survived immigrant parasites of low host specificity may in time succeed in establishing parasitism on/in the local hosts, which are generally (phylogenetically) closely related to the immigrant host. Certain remotely related local hosts may also become infested (or infected) if they possess the same ecological requirements as the immigrant host. A concurrent and reciprocal spreading of the native parasites (with low host specificity) to the immigrant host may also take place. Thus, a successful immigration will theoretically result in an exchange of parasites between the immigrant host and the native host(s). Moreover, the mixing of parasites is a function of time, the longer the sympatric habitation, the more mixing is the parasite fauna between the immigrant host and the native host(s).

In the early phase of parasite mixing, due to a necessary period of adaptation to the new macroenvironment (including both immigrant and native hosts), incidence of infestation (or infection) must be low. Generally, it is only after a longterm repeated trial that a parasite can eventually become established on or in a new host. Therefore, the incidence of the mixing of low host specific parasites is an indicator of the relative length of time that the immigrants have been present in the new region. In other words, an extremely low incidence or none mixing of the low host specific parasites should 
imply a relatively recent entry of the immigrant host and its parasite(s). Since the incidence of infestation (or infection) vary with season, locality, environmental parameters, and different host species, application of this hypothesis should be done with care. An accurate assessment of the parasite mixing in a new region can not be made without referring to the immigrant parasites' incidence of infestation (or infection) and seasonality in the other well-established regions. Furthermore, this hypothesis is only applicable to the case where a relatively recent migration has taken place.

The blue mussel, Mytilus edulis Linnaeus (as defined by Soot-Ryen, 1955), has a circumpolar distribution in the cold- and temperate-waters of both northern and southern hemisphere. According to Habe (1978), this species of mussel was first recorded from Japan in 1925 from the rafts used for oyster culture at a fisheries experimental station in Hyogo Prefecture. This species is suspected to have been unintentionally introduced into Japanese waters through the European and/or American merchant vessels visited the ports in the Inland Sea. Since blue mussel harbors an extremely low host specific copepod parasite, Pseudomyicola spinosus (Raffaele \& Monticelli), its occurrence in Japan will indicate, by applying the hypothesis developed above, whether the blue mussel is a recent immigrant to Japanese waters. Before making this analysis, we need information on the copepod parasites of Mytilus occurring both inside and outside of Japan.

\section{Copepod Parasites of Japanese Marine Mussels}

According to Soot-Ryen (1955), there are only three or possibly four species of mussels attributable to genus Mytilus. They are Mytilus edulis Linnaeus (with geographical subspecies), $M$. californianus Conrad, and $M$. coruscus Gould ( $=M$. crassitesta Lischke), and perhaps $M$. giganteus Nordmann. $M$. edulis is the most widely distributed species. In the northern hemisphere, it occurs in arctic waters extending south on Pacific coasts to Cabo San Lucas, Baja California in the west and Kyushu, Japan in the east; and on Atlantic coasts to North Carolina in the west and northern Africa in the east (including the Mediterranean and Black Sea). In the southern hemisphere, it is found in New Zealand, southern states of Australia, and both east and west coasts of Southern America (extending north to Brazil and Valparaiso, Chile, respectively).

Contrary to the world-wide distribution of $M$. edulis, $M$. californianus is confined to the Pacific coast of North America from the Aleutian Islands south to Islan Socorro, Mexico. $M$. coruscus has even more restricted distribution, it occurs only in Japan and southern Korea (Habe, personal communication).

While collecting on Sado Island, I was able to examine both species of Japanese Mytilus, as well as another species of marine mussel, Septifer virgatus (Wiegmann). It is regrettable to report that I was not able to examine again the same three species of mussels at the two subsequent collecting sites. I had only succeeded in examine $M$. edulis at Ogi, Ishikawa Prefecture and S. virgatus at Sirahama, Wakayama Pre- 
fecture. The following are the four species of parasitic copepods that were recovered from these three species of mussels.

\section{Pseudomyicola spinosus (Raffaele \& Monticelli)}

(Figs. 1A-I)

Material examined: $29 q$ and 16 o in mantle cavity of 32 Mytilus edulis (62 hosts examined) collected from the channel leading from Ryotsu Harbor into Kamoko Lake (a salt water lake) on Sado Island, 31 October, 1978; 201 ㅇ, 67 ๙ै, and 12 juveniles and copepodids in mantle cavity, esophagus, and stomach of $62 \mathrm{M}$. edulis (100 hosts examined) collected near Suzu, Ishikawa Prefecture, 7 November, 1978; 1 $\&$ and 1 o in mantle cavity of 1 Septifer virgatus (108 hosts examined) collected from Sirahama, Wakayama Prefecture, 28 November, 1978. Ten $q$ and 10 \% from M. edulis collected from Yokohama in Tokyo Bay by Dr. Ren Kuwabara, 11 August, 1976.

Remarks: Since this species has been excellently redescribed by Humes (1968), a detailed description based on the Japanese materials seems unnecessary. However, it is worthy of nothing that there are two different sizes of ovigerous females in a large collection made near Suzu, Ishikawa Prefecture. The smaller females (1.95$2.21 \mathrm{~mm}$ ) are consistent in carrying a pair of small egg sacs containing 4-6 eggs, while the larger females $(2.46-3.01 \mathrm{~mm}$ ) have their larger egg sacs containing 11-24 eggs (Fig. 1A). Nevertheless, there is no significant difference in the size of eggs from these two types of female. Only 14 such small ovigerous females were found in this collection of 201 females, they do not possess significant morphological difference in their appendages from the larger female. It is suspected that the adult female $P$. spinosus may continue to grow and produce more than one clutch of eggs, and the small ovigerous females represent the young reproducing adults.

The Japanese Pseudomyicola, $P$. ostreae Yamaguti, is herewith proposed to be synonymized with the cosmopolitan species, $P$. spinosus, because my close examination of the specimens of Pseudomyicola collected from four localities in Japan does not show significant morphological difference from the ones that were redescribed by Humes (1968). And, furthermore, the dissimilarities reported by Yamaguti (1936) for $P$. ostreae are obviously some fine details that are easily overlooked through an inadequate preparation followed with a cursory observation. Only two females were obtained and examined by Yamaguti and they are seemingly no longer in existence. An amendment to Yamaguti's original description of the Japanese Pseudomyicola is given in the following:

Female: The 3-segmented second antenna (Fig. 1D) bears a row of spinules on the first segment and one claw and 6 unequal elements (Fig. 1E) at the terminal end of the third segment. The mandible is as illustrated in Figure $1 \mathrm{~F}$ and the first maxilla (Fig. 1G) is armed with four unequal elements. The terminal segment of the second maxilla (Fig. 1H) is equipped with a short, blunt seta and a long, barbed 


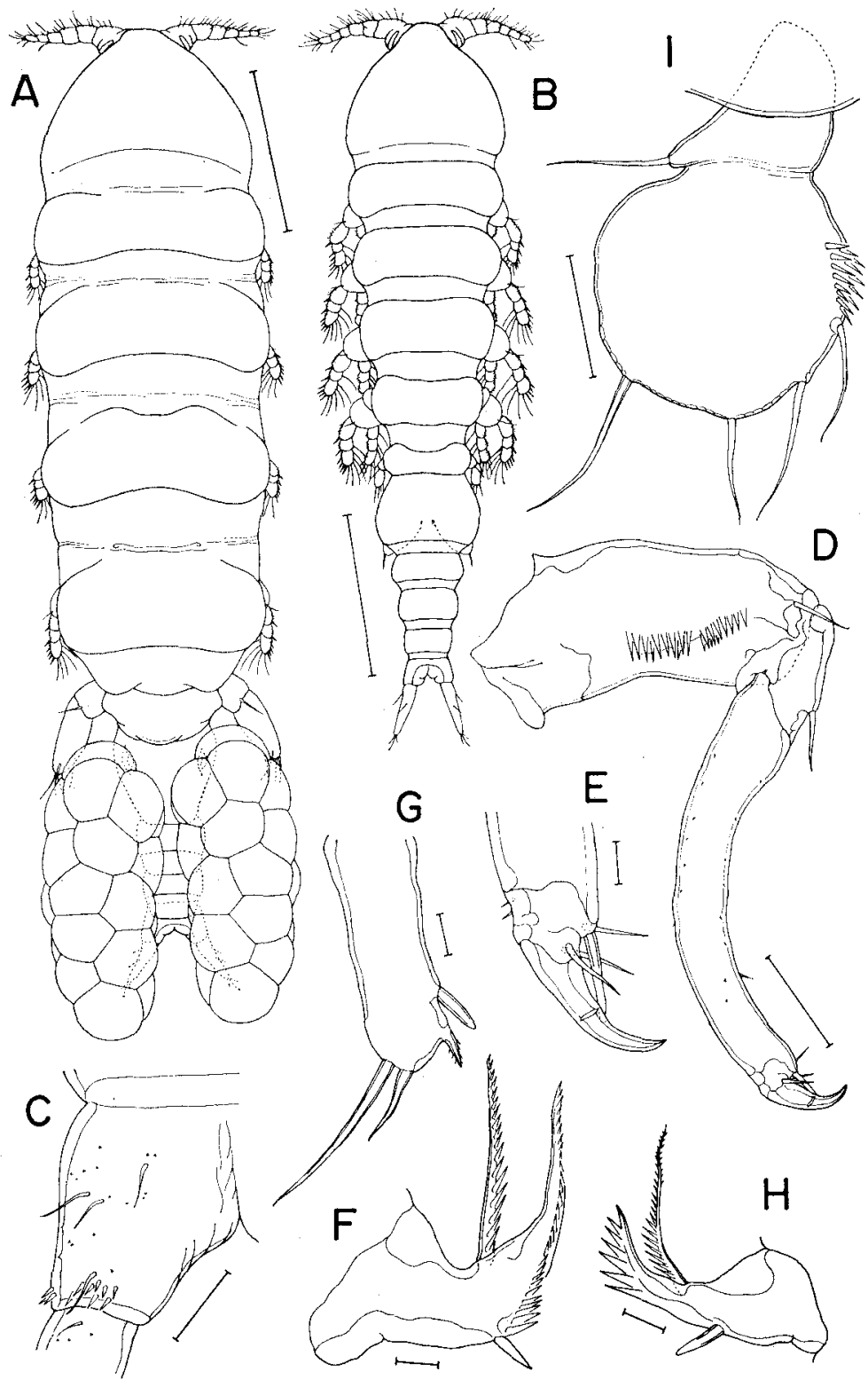

Fig. 1. Pseudomyicola spinosus (Raffaele \& Monticelli). A. ovigerous female, dorsal; B. mature male, dorsal. Female: $C$. right side of anal segment, ventral; D. second antenna; E. tip of second antenna; F. mandible; G. first maxilla; H. tip of second maxilla; I. fifth leg, inner view. Scale: $0.5 \mathrm{~mm}$ in A, B; 0.05 $\mathrm{mm}$ in $\mathrm{C}, \mathrm{D} ; 0.01 \mathrm{~mm}$ in $\mathrm{E}, \mathrm{F}, \mathrm{G}, \mathrm{H} ; 0.1 \mathrm{~mm}$ in $\mathrm{I}$. 
lash. The fifth leg (Fig. 1I) is indistinctly 2-segmented, with a subcircular-distal segment. The ventral surface of anal segment (Fig. 1C) has variable ornamentation as pointed out by Humes (1968: 205). Figure $1 \mathrm{C}$ shows the most ornamented specimen; some specimens even show difference in ornamentation between their right and left sides.

Male: The body (Fig. 1B) is highly variable in size, ranging from $1.36 \times 0.29$ to $2.08 \times 0.41 \mathrm{~mm}$. It bears numerous long setules on its body surface as in the female (not shown in either Fig. 1A or Fig. 1B).

\section{Modiolicola gracilicaudus Avdeev}

(Figs. 2A-F; 3A-L)

Material examined: 19 क, 9 a and 1 copepodid from 29 Mytilus coruscus (41 hosts examined) collected near Tassha Bay, Sado Island, 9 September, 1978; 35 ㅇ and $22 \sigma$ from $35 M$. coruscus (40 hosts examined) collected near Tassha Bay, Sado Island, 12 September, 1978.

Remarks: Modiolicola gracilicaudus was first reported from Crenomytilus grayanus (Dunker) in Posiet Bay in the far estern Russia. The present report is the second recording of this copepod. The following notes are intended to supplement Avdeev's (1977) original description.

Female: The body (Fig. 2A) measurements are from $1.64 \times 0.72$ to $1.81 \times 0.74$ $\mathrm{mm}$. A fully grown egg sac extends posteriorly beyond the tip of the caudal ramus. The rostrum and the labrum are as illustrated in Figure 2B. The egg sac attachment area (Fig. 2C) bears two small setae with a blunt process between them. The posteroventral border of the genital segment and the three abdominal segments bear a striated cuticular membrane with serrated edge (Fig. 2D), which appears as a row of spines when observed at a low magnification. The caudal ramus (Fig. 2E) is about 4.3 times as long as wide and bears 6 naked elements. The first antenna (Fig. 2F) is 7-segmented; the formula for the armature is $4,13,6,3,4+1$ aesthete, $2+1$ aesthete, and $7+1$ aesthete. The tip of the second antenna (Fig. 3A) is armed with 3 claws and 4 unequal setae. The second maxilla (Fig. 3B) has 2 extremely unequal setae on the terminal segment. The maxilliped (Fig. 3C) has two setules close to the terminal attenuated process. There is a patch of small denticles near the base of each outer spine on the second and third segments of the exopod of leg 1 (Fig. 3D). The terminal segment of the endopod of leg 2 (Fig. 3E) and leg 3 (Fig. 3F) bears spinules at the base of each plumose seta. The spinules on the third endopod are not as heavy as those on the second endpod. The endopod of leg 4 bears spinules on the second and third segments as illustrated in Figure 3G. The fifth leg (Fig. 3H) has a small basal swelling. A pair of spermatophores (Fig. 3L) with a thick wall and a thin common duct were found attached to the genital opening of a female bearing no egg sacs.

Male: The body (Fig. 3I) measurements are from $1.54 \times 0.53$ to $1.70 \times 0.58$ 
$\mathrm{mm}$. The second segment of the maxilliped is armed with rows of teeth and two setae as illustrated in Figure 3J. The fifth leg (Fig. 3K) is slightly different from the female.

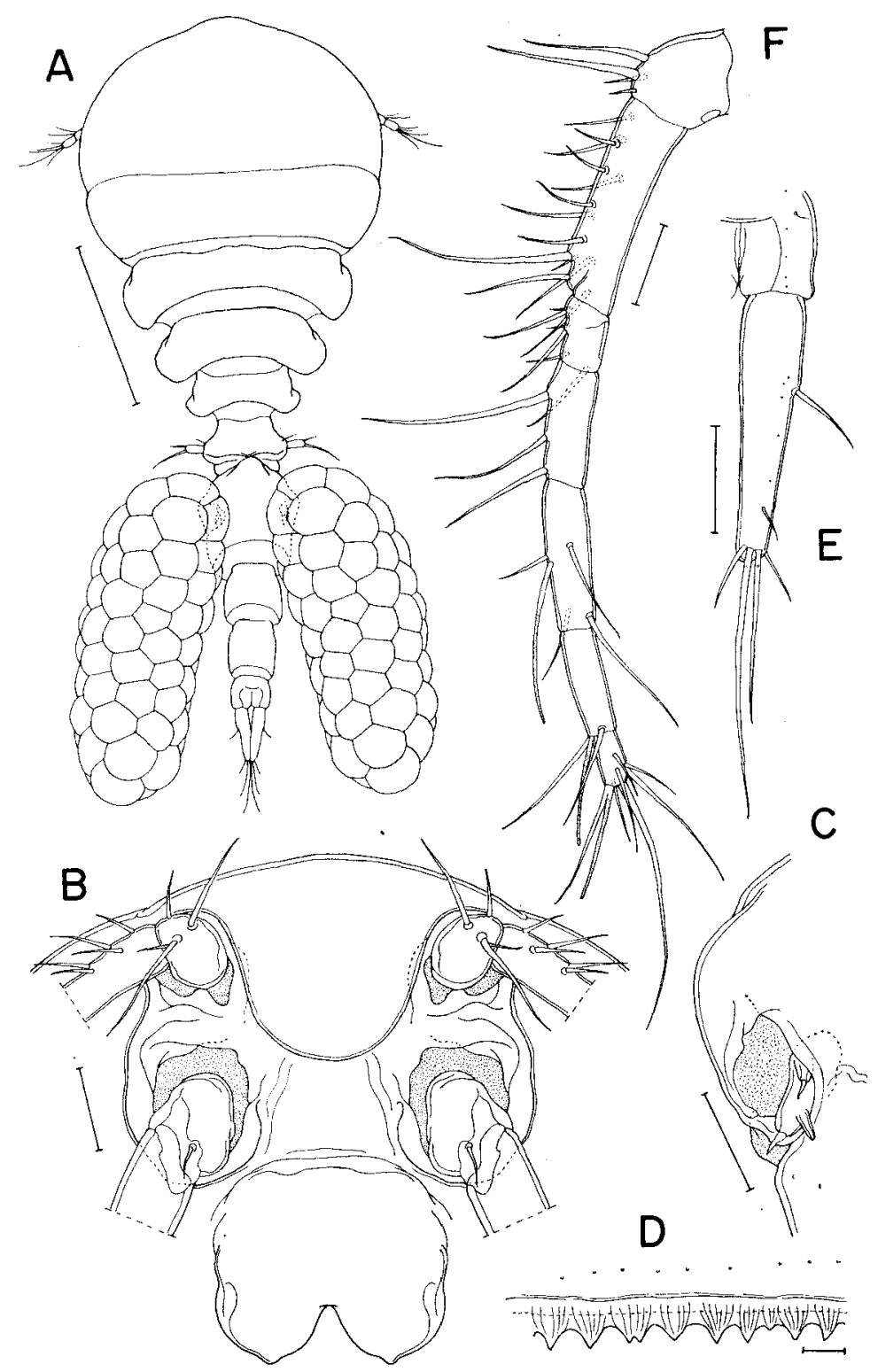

Fig. 2. Modiolicola gracilicaudus Avdeev, female. A. ovigerous female, dorsal; B. rostral area and labrum; C. sixth leg and egg sac attachment area; D. posterior edge of genital segment, ventral; E. caudal ramus; $F$. first antenna. Scale: $0.5 \mathrm{~mm}$ in $\mathrm{A} ; 0.05 \mathrm{~mm}$ in $\mathrm{B}, \mathrm{C}, \mathrm{E}, \mathrm{F} ; 0.01 \mathrm{~mm}$ in D. 


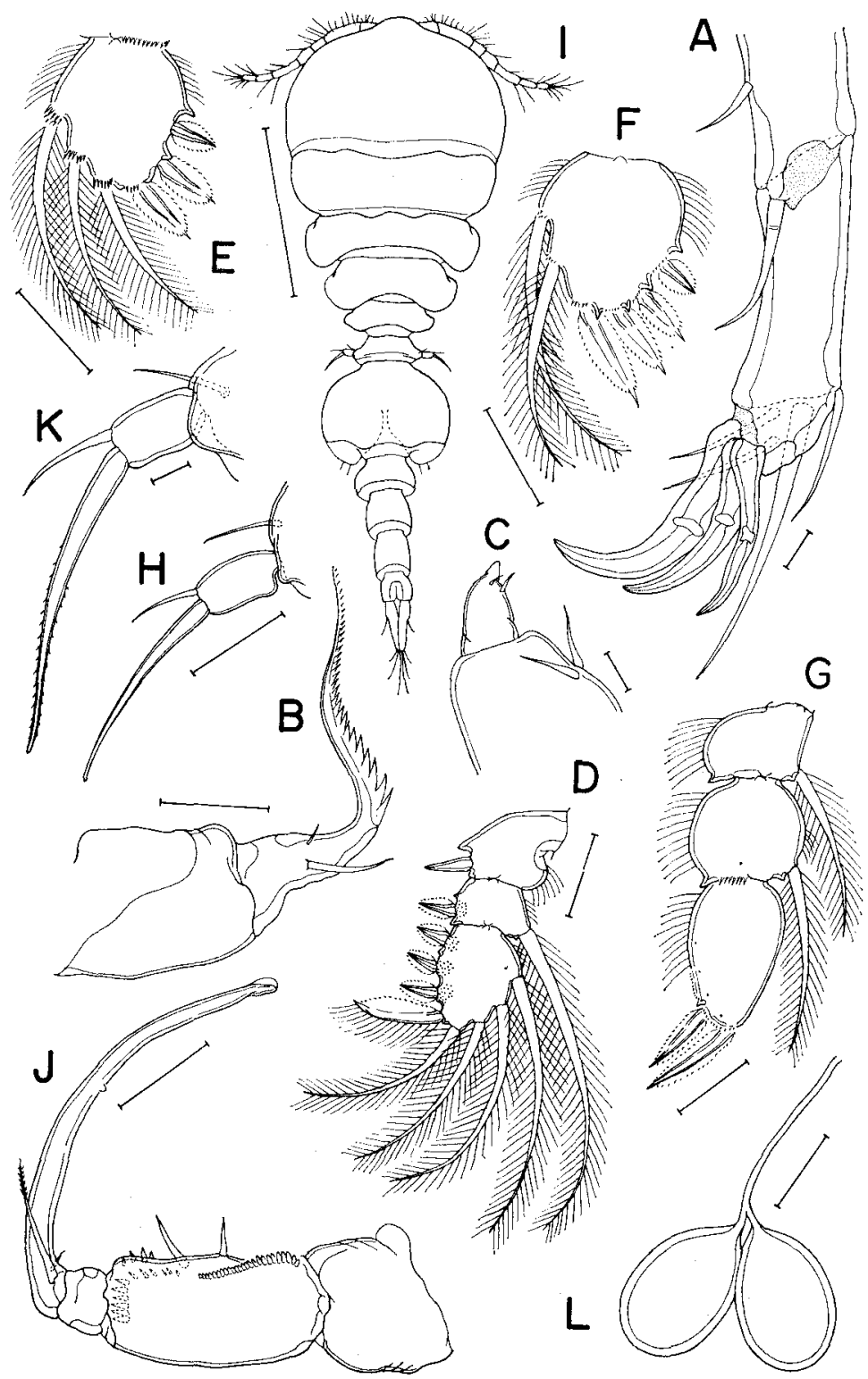

Fig. 3. Modiolicola gracilicaudus Avdeev. Female: A. tip of second antenna; B. second maxilla; C. tip of maxilliped; D. exopod of first leg; E. terminal segment of second endopod; F. terminal segment of third endopod; G. endopod of leg 4; $\mathrm{H}$. fifth leg. Male: I. mature male, dorsal; J. maxilliped; K. fifth leg; L. spermatophores. Scale: $0.01 \mathrm{~mm}$ in A, C, K; $0.05 \mathrm{~mm}$ in B, D. $\mathrm{E}, \mathrm{F}, \mathrm{G}, \mathrm{H}, \mathrm{J} ; 0.5 \mathrm{~mm}$ in $\mathrm{I} ; 0.1 \mathrm{~mm}$ in $\mathrm{L}$. 


\section{Lichomolgus sadoensis n. $\mathrm{sp}$.}

(Figs. 4A-K; 5A-J)

Material examined: 6 ㅇ, 3 o and 1 copepodid from washings of 18 Septifer virgatus collected in Tassha Bay, Sado Island, 5 September, 1978. Holotype 우, allotype, and 5 paratypes deposited in the U.S. National Museum of Natural History (Smithsonian Institution), Washington, D. G; the remaining paratypes (dissected) in the author's collection.

Female: The body (Fig. $4 \mathrm{~A}$ ) measurements are from $1.33 \times 0.54$ to $1.81 \times 0.56$ $\mathrm{mm}$. There is a prominent rostrum (Fig. 4B) erecting between the bases of the antennae. The urosome (Fig. 4C) is distinctly shorter than half of the body. The genital segment bears a pair of ventral sclerites as illustrated in Figure 4D. The areas of attachment of the egg sacs are situated dorsolaterally (Fig. 4C). Each area bears 3 elements representing the rudimentary leg 6 as illustrated in Figure 4E. The posteroventral border of the genital segment and the three abdominal segments are smooth and free of ornaments. The caudal ramus is about 4.2 times as long as wide and bears 6 unornamented elements. All egg sacs were broken, the egg is about $85 \mu$ in diameter.

The first antenna (Fig. 4F) is rather short, it is segmented and armed as in the other species of Lichomolgus. The 4-segmented second antenna (Fig. 4G) is characteristic in having a formula of $1,1,1$, and IV +2 , with an extremely small elements on the first three segments. The labrum (Fig. 4H) is not highly sclerotized. The mandible (Fig. 4I) is a typical Lichomolgus-form, but the first maxilla (Fig. 4I) is unusual in bearing 3 elements with a protruded innerdistal corner. The second maxilla (Fig. 4J) and the maxilliped (Fig. 4K) are not much different from the other species of Lichomolgus.

The formula for the armature of legs $1-4$ is of typical in Lichomolgus. The endopods of the first three pairs of legs (Figs. 5A, 5C, 5D) bear different numbers of spines and setae in its terminal segment. An abnormally developed first endopod (Fig. 5B) was seen on the left side of an ovigerous female. The second segment of the fourth endopod (Fig. 5E) is variable in its dimension, ranging from 3.02 as long as wide to 3.64 as long as wide. Another abnormally developed endopod in the fourth leg (Fig. 5F) is seen on the left side of another ovigerous female. The fifth leg (Fig. 5G) is short and broad and armed with a spine and a naked seta at the tip of the free segment.

Male: The body (Fig. $5 \mathrm{H}$ ) measurements are from $1.01 \times 0.36$ to $1.05 \times 0.40$ $\mathrm{mm}$. The urosome is different from female in the form of the genital segment and addition of an abdominal segment. The rudimentary sixth leg (Fig. 5I) is represented by two naked setae located at the tip of a posteroventral flap on the genital segment. The caudal ramus is relatively longer than in the female, it is about 5.3 as long as wide.

The first antenna shows a secondary sexual dimorphism in bearing an aesthete 


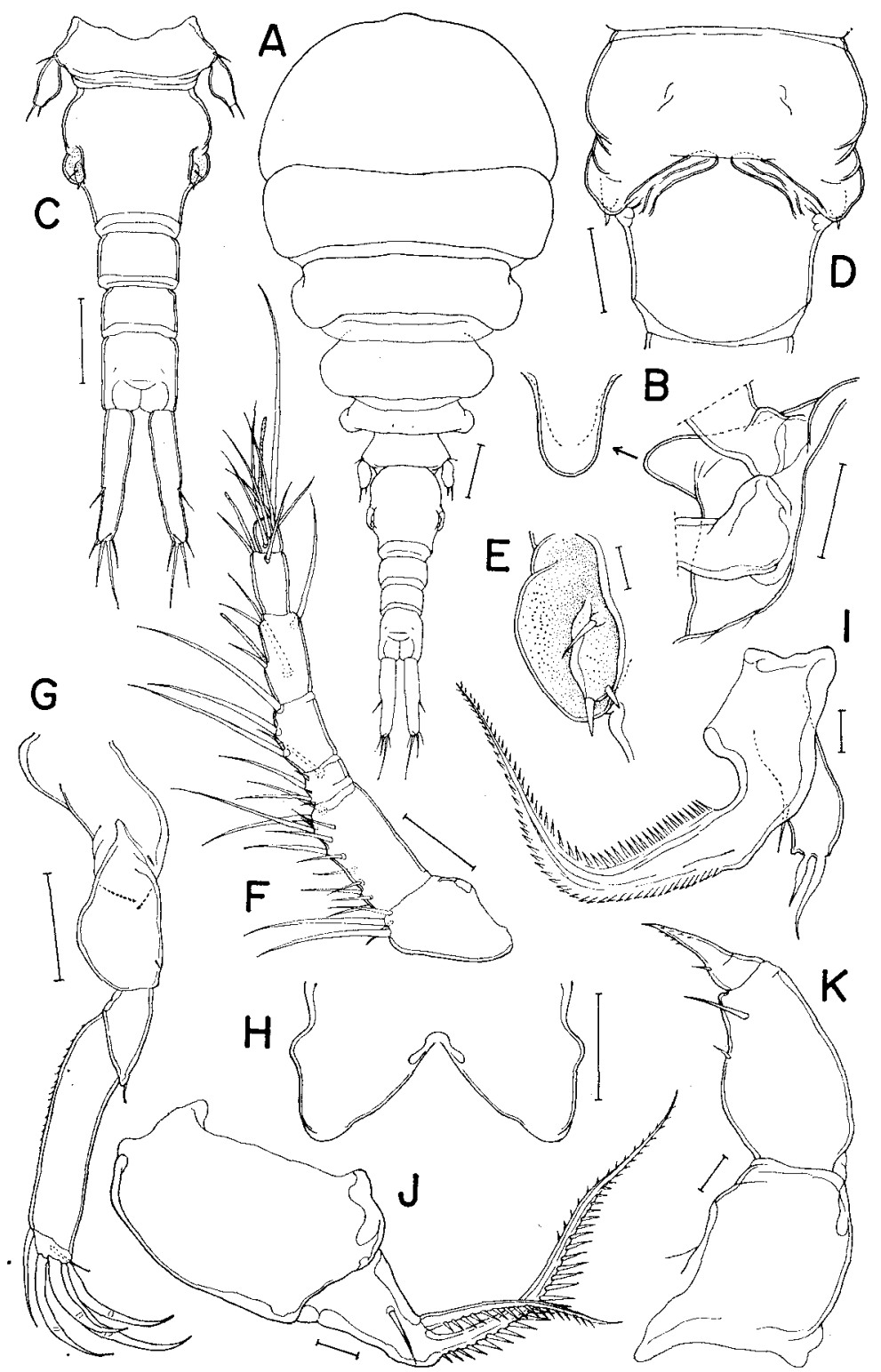

Fig. 4. Lichomolgus sadoensis n. sp., female. A. ovigerous female, dorsal (egg sacs broken); B. rostrum (lateral view and ventral view) and rostral area (lateral view); C. urosome, dorsal; D. genital segment, ventral; E. egg sac attachment area and sixth leg; F. first antenna; G. second antenna; H. labrum; I. mandible and first maxilla; J. second maxilla; K. maxilliped. Scale: 0.1 $\mathrm{mm}$ in $\mathrm{A}, \mathrm{C} ; 0.05 \mathrm{~mm}$ in $\mathrm{B}, \mathrm{D}, \mathrm{F}, \mathrm{G}, \mathrm{H} ; 0.01 \mathrm{~mm} \mathrm{E}, \mathrm{I}, \mathrm{J}, \mathrm{K}$. 


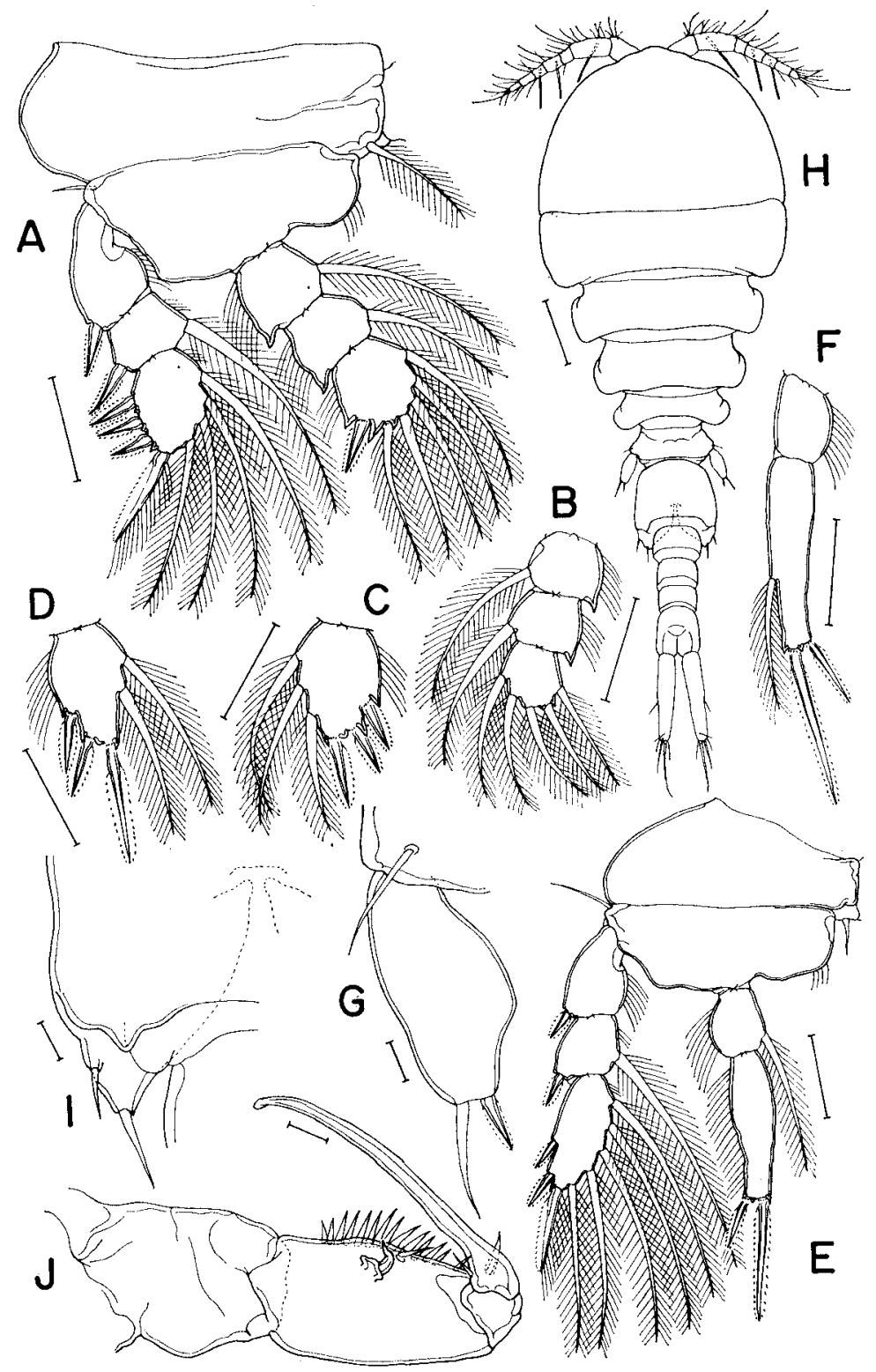

Fig. 5. Lichomolgus sadoensis n. sp. Female: A. leg 1; B. abnormal first endopod; C. terminal segment of second endopod; D. terminal segment of third endopod; E. leg 4; F. abnormal fourth endopod; G. leg 5. Male: H. mature male, dorsal; I. leg 6; J. maxilliped. Scale: $0.05 \mathrm{~mm}$ in A, B, C, D, E, F; $0.01 \mathrm{~mm}$ in $\mathrm{G}, \mathrm{I}, \mathrm{J} ; 0.1 \mathrm{~mm}$ in $\mathrm{H}$. 
on the second, fourth, and fifth segments, respectively. The rostrum, second antenna, labrum, mandible, first maxilla, and second maxilla, are like those of the female. The maxilliped (Fig. 5J) is stout and 4-segmented. The first and the fourth segment are unarmed, but the second segment is armed with a row of long spines, one seta, and one bent spinous process situated on a heavily sclerotized hooklike process. The fourth segment, represented by the base of the terminal claw, is armed with two elements.

Legs 1-4 like those of the female except the spines on the first and the second endopod are relatively heavier. The fifth leg is similar to that of the female but smaller.

Remarks: Three species of Lichomolgus have been reported from Japan. They are L. spondyli Yamaguti, 1936; L. inflatus Tanaka, 1961; and L. sepiae Izawa, 1976. However, the last species should be transferred to Metaxymolgus, because its mandible, female maxilliped, male first antenna, and male first endopod, as described by Izawa (1976), are apparently characteristics of Metaxymolgus and not Lichomolgus.

Eighteen species of Lichomolgus were listed by Humes and Stock (1973) and only two valid species, L. hippopi Humes, 1976 and L. uncus Jones, 1976, were added since then. Among these 20 species of Lichomolgus there is only one, L. elegantulus Stock, 1960, that like $L$. sadosensis has four claws on the second antenna. These two species can be easily separated by the differences exhibited in the shape of the cephalosome, the shape of the genital segment, the dimension and armature of the caudal ramus, the maxilliped, and the fifth leg. L. elegantulus is known only of the female, it was reported from a bivalve, Pteria hirundo (Linnaeus), in Banyuls, France by Stock (1960).

\section{Lichomolgus bidentipes $\mathrm{n}$. $\mathrm{sp}$.}

(Figs. 6A-I; 7A-F)

Material examined: 7 ovigerous o from mantle cavity of 5 Septifer virgatus (108 hosts examined) collected from Sirahama, Wakayama Prefecture, 28 November, 1978. Holotype and 4 paratypes deposited in the U. S. National Museum of Natural History (Smithsonian Institution), Washington, D.C.; the dissected paratypes in the author's collection.

Female: The body (Fig. 6A) measurements are from $1.05 \times 0.45$ to $1.48 \times 0.54$ $\mathrm{mm}$. The posteroventral border of the genital segment and the first two abdominal segments are ornamented as shown in Figure 6B. The rudimentary leg 6 is located in the area of attachment of the egg sac (Fig. 6C). The caudal ramus (Fig. 6D) is about 4.3 times as long as wide and bears two long terminal elements (see Fig. 6A). Egg sacs are large, containing numerous small eggs.

The first antenna (Fig. 6E) is slender than that of the previous species, but it is similarly segmented and armed. The second antenna (Fig. 6F) has slender third and fourth segments, the formula of the armature is 1, 1, 3 and IV+2. One of 


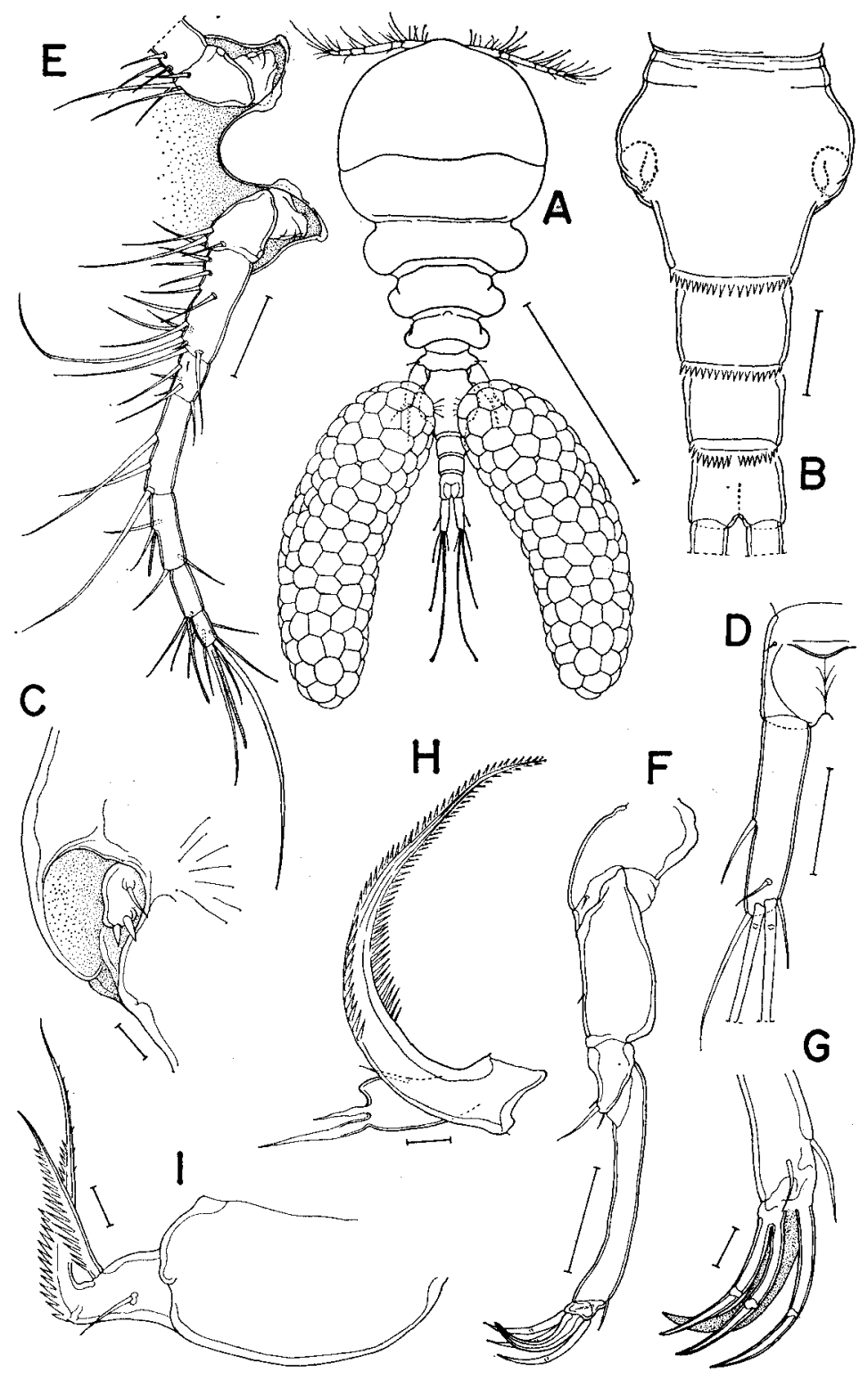

Fig. 6. Lichomolgus bidentipes n. sp., female. A. ovigerous female, dorsal; B. genital segment and abdomen, ventral; C. egg sac attachment area and leg 6; D. caudal ramus; E. rostrum and first antenna; F. second antenna; G. tip of second antenna; H. mandible and first maxilla; I. second maxilla. Scale: $0.5 \mathrm{~mm}$ in $\mathrm{A} ; 0.05 \mathrm{~mm}$ in $\mathrm{B}, \mathrm{D}, \mathrm{E}, \mathrm{F} ; 0.01 \mathrm{~mm}$ in C,G.H,I. 
the four terminal hooks (Fig. 6G) is distinctively larger than the other three. The labrum, mandible (Fig. 6H), first maxilla (Fig. 6H), second maxilla (Fig. 6I), and maxilliped (Fig. 7A) are not much different from those of $L$. sadoensis.

The formula for the armature of legs 1-4 is of typical in Lichomolgus. The endopods of the first three pairs of legs bear different numbers of spines and setae in their terminal segments (Figs. 7B, 7C, 7D). The second segment of the fourth

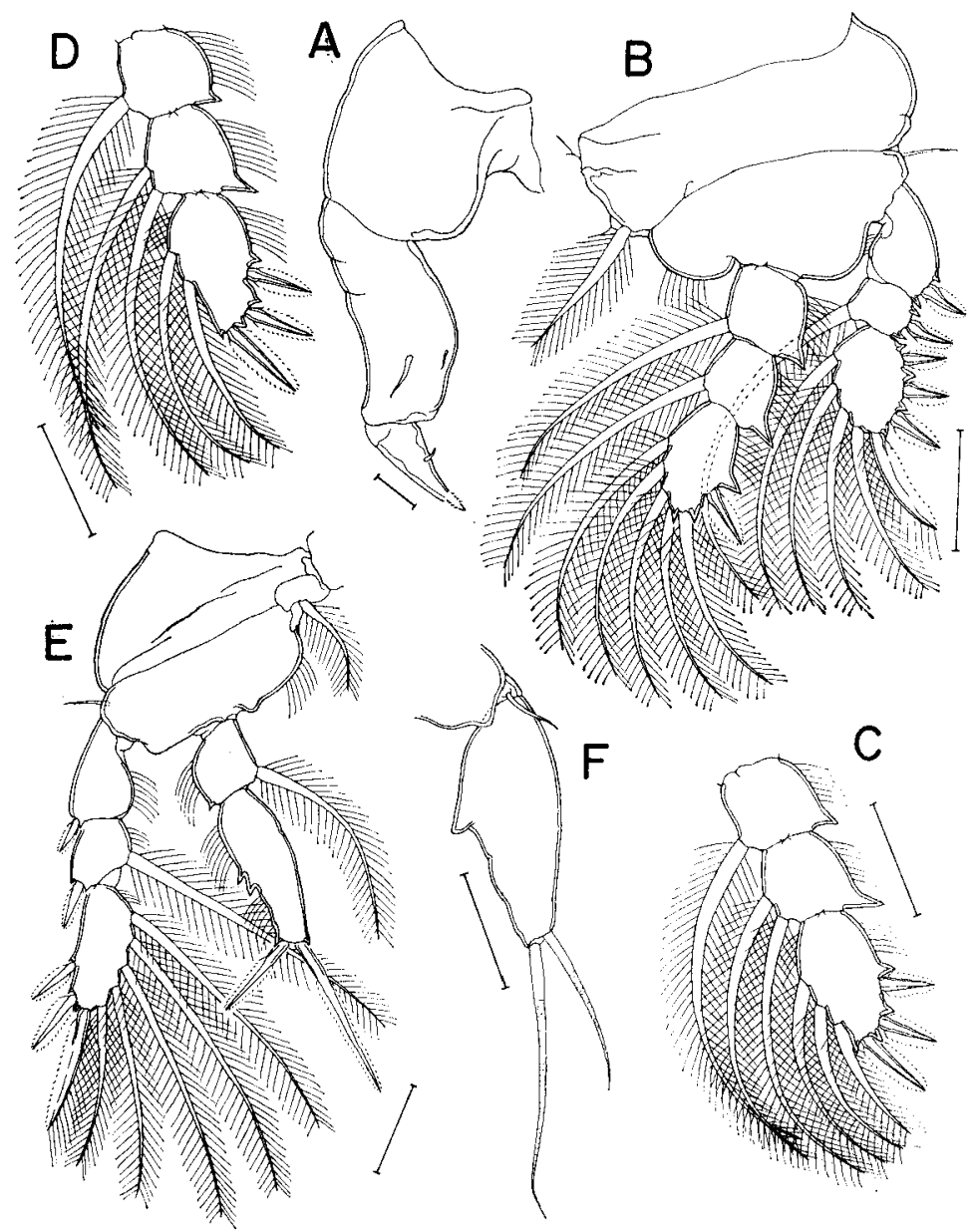

Fig. 7. Lichomolgus bidentipes n. sp., female. A. maxilliped; B. leg 1; C. second endopod; D. third endopod; E. leg 4; F. fifth leg. Seale: $0.01 \mathrm{~mm}$ in A; $0.05 \mathrm{~mm}$ in $\mathrm{B}, \mathrm{C}, \mathrm{D}, \mathrm{E}, \mathrm{F}$.

endopod (Fig. 7E) bears two denticulate projections on the outer surface. The fifth leg (Fig. 7F) has a pointed basal protrusion and attenuated distal end. The two terminal setae are long and naked.

Remarks: This is the third species of Lichomolgus with four claws on the second antenna. It can be easily distinguished from the other two species, L. elegantulus 
and $L$. sadoensis, by the possession of two outer denticulate projections on the second segment of the fourth endopod (Fig. 7E) and a large basal pointed process on the fifth leg (Fig. 7F). The nature of the four terminal hooks on the second antenna is also a good distinguishing characteristic.

\section{Copepod Parasites of Mytilus edulis Linnaeus}

Although the blue mussel has a world-wide distribution with a great abundance in the cold- and temperate-waters of both northern and southern hemisphere, its copepod parasites are very poorly known. Only some of those inhabiting the northern hemisphere have so far been examined for their parasites. Table 1 summarizes the general localities of the blue mussel with their reported copepod parasites.

Pseudomyicola spinosus has the widest distribution among the seven reported parasitic copepods. It is not only known from the blue mussel, but has also been reported from thirty-nine species of bivalves occurring in the tropical and warmtemperate waters of the Atlantic (Humes, 1968). In the South Pacific, it has been reported occurring abundantly in the digestive tract of Rock Oyster, Crassostrea glomerata, in New Zealand (Dinamani \& Gordon, 1974). Therefore, it is a parasite with a very low host specificity to the bivalves.

The blue mussel is primarily an animal of the cold and cold-temperate waters, whereas $P$. spinosus is primarily a warm-water parasite. This species of copepod has so far not yet been reported from the European blue mussels occurring on the coast of British Isle, Denmark, or Germany. And on the Pacific coast of North America, it is only known from the coast south of Point Conception, California - a landmark being referred to as the boundary between the warm-temperate and the cold-temperate waters in the eastern North Pacific (Briggs, 1974).

Unlike $P$. spinosus, the intestinal parasite of the blue mussel in Europe, $M y$ tilicola intestinalis, has its distribution nearly coincide with its host in both warmand cold-temperate waters. It is a parasite indigenous to European waters and has so far not been reported outside of Europe. However, its oriental counterpart, Mytilicola orientalis, has quite a different pattern of distribution. $M$. orientalis was first reported by Mori (1935) from two species of Japanese bivalves near Hiroshima, the Pacific Oyster, Crassostrea gigas (Thumberg), and the Japanese mussel, Mytilus coruscus Gould ( $=M$. crassitesta Lischke), but it is also known to occur in the mussels on the west coast of North America.

The occurrence of $M$. orientalis in the blue mussels of the Pacific coast of North America is a pure artifact, resulted from the introduction of Pacific Oyster from Japan for cultivation (Wilson, 1938). According to Barrett (1963), mature oysters from Japan were first planted in Puget Sound, Washington in 1875. After numerous repeated transplanting, the Pacific Oyster had finally become firmly established in Washington in the 1920's and its intestinal copepod parasite, M. orientalis (=M. ostreae Wilson) was subsequently recorded by G.B. Wilson in 1938 from the 
oysters in Puget Sound.

It is interesting to note that although $M$. orientalis is a common parasite in northern California occurring with high incidence in both species of Mytilus (Chew, Sparks \& Katkansky, 1964; Bradley \& Siebert, 1978), it has so far not yet been found in either species of Mytilus in southern California (Ho, unpublished). This paucity of $M$. orientalis on the coast of southern California is probably due to the absence of large scale and consistent operation of oyster culture south of San Francisco Bay.

There are three species of Modiolicola that inhabit the mantle cavity of blue mussel. Unlike their host, they exhibit a distinctly disjunct distribution. Modiolicola insignis is found only in Eorupean waters, M. gracilis is confined to Pacific coast of North America, and $M$. gracilicaudus is so far only known from the Sea of Japan.

The European Modiolicola occurs also in other genus of mussels (Modiola) and the American species has also been found in other bivalves, the Pismo clam, Tivela stultorum (Mawe) (Ho, unpublished). According to Avdeev (1977), two species of Modiolicola, M. bifida and $M$. gracilicaudus, were found in the mussel, Crenomytilus grayanus (Dunker), in Posiet Bay in the western part of the Sea of Japan (see Fig. 8). However, in Japan, only $M$. gracilicaudus is recovered from the mussels on the Sado

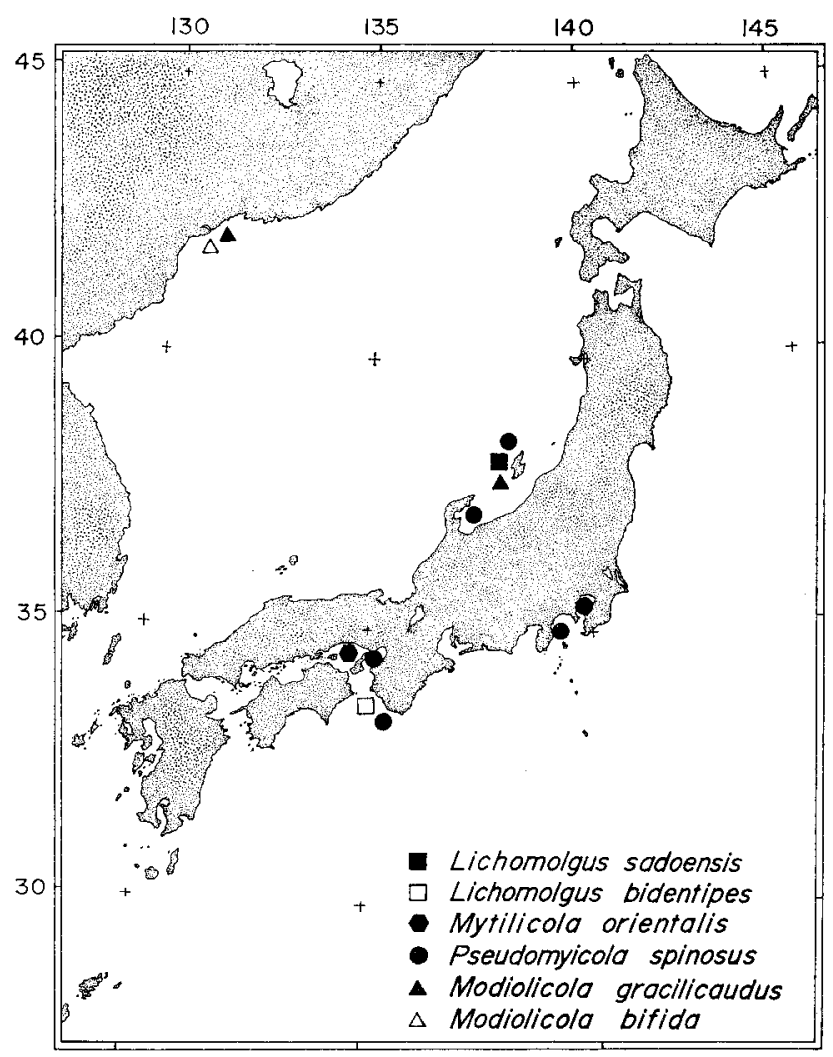

Fig. 8. Copepod parasites of marine mussels in Japan and its vicinity. 
Island and $M$. bifida is known as nonemytilid parasite in Kyushu (Tanaka, 1961; Ko, Murakami \& Daiku, 1962).

The harpacticoid parasite of the blue mussel, Tisbe celata, is so far only known from St. Andrews, New Brunswick, Canada. It has not been recorded from any other place since Hume's (1954) original report. This is a rather unusual harpacticoid copepods, as a great majority of the species of Tisbe are freeliving.

\section{Implication of Copepod Parasites on Zoogeography of Japanese Mytilus edulis Linnaeus}

The genus Mytilus as defined by Soot-Ryen (1955) seems to be of a relatively recent origin, because no known fossil records are older than Pliocene period. However, based on the recent distribution of $M$. edulis, Soot-Ryen suspected this species must be rather old, and Grant (1931) postulated that the earliest occurrence of $M$. edulis on the Pacific coast of North America might be in the early Miocene. Although both of the remaining species of Mylilus ( $M$. californianus and $M$. coruscus) are recorded from Pleistocene period, the California mussel may have originated earlier than the Japanese mussel, as the former has a much wider distribution in the North Pacific than the latter.

The fossil records clearly indicate that the California mussel must have been cohabiting with blue mussel in the Eastern North Pacific since, at least, Pleistocene period. In this more than one million years of sympatric existence, any parasite of low host specificity should, according to the hypothesis proposed above, have been well mixed between the two species of mussels. The three species of copepods listed in Table 1 for $M$. edulis inhabiting the west coast of North America are in fact also known to occur in $M$. californianus in California.

As to be expected, based on the parasitism of Mytilicola orientalis in M. edulis in California, this introduced intestinal parasite has been so far recorded only from those $M$. californianus living in the northern part of the coast where the Pacific Oyster is cultured.

Although Modiolicola gracilis is known from $M$. californianus in both central and southern California, Pseudomyicola spinosus has been so far known only from those living in southern California (Ho, unpublished). As discussed above in relation to $M$. edulis, the paucity of $P$. spinosus in the central and northern California is due to its nature of being a warm-water parasite. However, the absence of $M$. gracilis from the Pacific coast north to the central California is probably an artifact (lack of parasite survey), because the European species of Modiolicola ( $M$. insignis) is common on the coast of Germany (Dethlefsen, 1971) where the water temperature is too low for the survival of $P$. spinosus.

According to the account on the history of oyster culture on the west coast of North America (Barrett, 1963), M. orientalis could not have been introduced to California until in the early 1930's. However, this immigrant parasite established its parasit- 
Table 1. Distribution of copepod parasites of blue mussel, Mytilus edulis Linnaeus

\begin{tabular}{|c|c|c|c|c|c|}
\hline $\begin{array}{l}\text { Locality } \\
\text { Copepod parasites }\end{array}$ & Europe & $\begin{array}{l}\text { East coast } \\
\text { of North } \\
\text { America }\end{array}$ & $\begin{array}{l}\text { West coast } \\
\text { of North } \\
\text { America }\end{array}$ & $\begin{array}{l}\text { Pacific } \\
\text { coast of } \\
\text { Japan }\end{array}$ & $\begin{array}{l}\text { Sea of } \\
\text { Japan }\end{array}$ \\
\hline \multicolumn{6}{|l|}{ Harpacitoida } \\
\hline $\begin{array}{l}\text { Family Tisbidae } \\
\text { Tisbe celata Humes }\end{array}$ & & $\mathrm{x}$ & & & \\
\hline \multicolumn{6}{|l|}{ Cyclopoida } \\
\hline $\begin{array}{l}\text { Family Sabelliphilidae } \\
\text { Modiolicola gracilis Wilson }\end{array}$ & \multicolumn{4}{|c|}{ Family Sabelliphilidae } & \\
\hline $\begin{array}{l}\text { Modiolicola gracilicaudus Avdeev } \\
\text { Modiolicola insignis Aurivillius }\end{array}$ & $x$ & & & & $\mathrm{x}$ \\
\hline \multicolumn{6}{|l|}{ Family Clausiidae } \\
\hline Mytilicola intestinalis Steur & $\mathrm{x}$ & & & & \\
\hline Mytilicola orientalis Mori & & & $\mathrm{X}$ & & \\
\hline Family Myicolidae & & & & & \\
\hline Pseudomyicola spinosus (R. \& M.) & $\mathrm{x}$ & $\mathrm{x}$ & $\mathrm{x}$ & $\mathrm{x}$ & $\mathrm{x}$ \\
\hline
\end{tabular}

Note: These data were compiled from the following references: Avdeev (1977); Bradley \& Siebert (1978); Chew, Sparks \& Katkansky (1964); Dethlefsen (1972); Grainger (1951); Humes (1954); Humes (1968); Humes \& Stock (1973); Korringa (1953); Monod \& Dollfus (1932); Mori (1935); Odlaug (1946); Steuer (1903); and Williams (1969).

ism rather quickly in both species of Mytilus on the Pacific coast. In 1963, only after being introduced to California for about one-third of a century, the incidence of infestation of this parasite in Humbolt Bay, California was reported to be as high as $58.3 \%$ in $M$. edulis and $65 \%$ in M. californianus (Chew, Sparks \& Katansky, 1964). Such a quick establishment of immigrant parasite in the local hosts is an indication that in Japan Mytilus coruscus, rather than Crassostrea gigas, is the primary host to $M$. orientalis. Although the oyster is responsible for carrying the parasite into North America, the phylogenetically closer local hosts $-M$. edulis and $M$. californianus provided the immigrant parasite a least altered microenvironment over the local oysters and led it to a quick establishment in the new region. A recent survey on the parasitism of this introduced intestinal parasite in San Francisco Bay by Bradley and Siebert (1978) has clearly shown that in the field $M$. orientalis prefer $M$. edulis to native oyster, Ostrea lurida Carpenter. While the incidence of infection in the mussel ranges from $36.8 \%$ (in summer) to $48.5 \%$ (in winter), the highest rate in the oyster is only $2.7 \%$ (in summer). A similar host preference also exists in the European species of Mvtilicola. Hepper (1953) has experimentally established that the blue mussel, but not the oyster, was readily infected by $M$. intestinalis when both hosts were exposed to the infective stage of the parasite.

The incidence of infestation of $P$. spinosus in southern California is higher in $M$. edulis (from 64 to $100 \%$; Gustafson, in preparation) than in $M$. californianus (from 2.3 to $24.7 \%$; Ho, unpublished). However, the reverse is true in the case of $M$. gracilis, it is 7.8-63.9\% in M. californianus and 1.4-28.9\% in M. edulis (Ho, unpublished). 
These data indicate that there might be a competition for food and shelter existing between the species of Pseudomyicola and Modiolicola, with the former being more successful in $M$. edulis than in $M$. californianus, and vice versa in the latter parasite. Nevertheless, it clearly shows that all three species of copepod parasites have been fairly well mixed between $M$. edulis and $M$. californianus - an indication of longterm sympatric existence of the hosts.

After critically reviewing and analyzing the present status of parasite mixing in southern California, let us now turn to the examples in Japan.

My field data indicates that the incidence of infestation of $P$. spinosus in $M$. edulis in the Sea of Japan is rather high, it is $51.6 \%$ on Sado Island and $62 \%$ on Noto Peninsula, with a notable absence of this parasite from the samples of $M$. coruscus examined. It is remarkable that, inspite of its extremely high incidence of infestation in $M$. coruscus $(70.7 \%$ and $87.5 \%$ in the samples collected and examined on September 9 and 12,1978, respectively), M. gracilicaudus was not found at all in the specimens of $M$. edulis examined on Sado Island.

The above preliminary findings from the Sea of Japan indicate that the immigrant parasite ( $P$. spinosus) is still absent from the local host $(M$. coruscus) and the local parasite ( $M$. gracilicaudus) is still absent from the immigrant host ( $M$. edulis). In other words, the mixing of the low host specific parasites between the immigrant host and the local host has not yet taken place in this region and, according to the hypothesis proposed above, $M$. edulis must be a recent immigrant to the Sea of Japan.

From the fact that the specimens of Septifer virgatus, a close relative of Mytilus, examined at Sirahama yielded an incidence of $0.9 \%$ of $P$. spinosus but none of them examined on Sado Island carried this parasite, one might entertain a thought that the blue mussel have reached the Pacific coast of Japan before coming to the Sea of Japan. However, M. edulis could not have lived on the Pacific coast of Japan for a long time, because the incidence of the occurrence of immigrant parasite is still very low in the local host, S. virgatus. Although Hoshina \& Sugiura (1954) have reported the discovery of $P$. spinosus in the mantle cavity of a clam, Laternula kamakurana Pilsbry, from Kanazawa Bay in Kanagawa Prefecture, the incidence there is very low too, it is only $0.5 \%$.

The oriental Mytilicola, $M$. orientalis, has not yet been reported from $M$. edulis in Japan. However, based on the parasitological data recorded from the west coast of North America, this intestinal parasites should be present in the immigrant host (M. edulis) in Japan, at least in those mussels which inhabit the Inland Sea and other parts of the Pacific coast.

Sixty-seven species of marine mussels (Mytilidae) are known to occur in Japan. However, Dr. Tadashige Habe of National Science Museum in Tokyo has informed me that only four species of them are common in Japan, these are: Mytilus edulis Linnaeus (the introduced species), Septifer virgatus (Weigmann), Modiolus auriculatus (Krauss), and Musculus senhousis (Benson). They are all widely distributed, ranging from Hokkaido to Ryukyu Islands, except $M$. auriculatus which is absent from Hok- 
kaido. As shown in Figure 8, the existing information of the copepod parasites of Japanese marine mussels is far from complete, a systematic survey of them from different parts of Japan, especially on these four most common species of mussels, is highly desirable for further testing of the proposed dispersal of $M$. edulis in Japan.

The blue mussel in Japan has been called Mytilus edulis galloprovincialis Lamarck (Habe, personal communication), with a connotation that the Japansee blue mussel is originated from Europe, particularly the Mediterranean. However, there is a possibility of finding out the origin of Japanese blue mussel by using the indicator parasites. As being discussed above, Modiolicola insignis and $M$. gracilis are known to occur in the mantle cavity of $M$. edulis in Europe and west coast of North America, respectively. Therefore, a discovery of $M$. insignis in Japanese mussels will indicate an European origin and $M$. gracilis, an American origin. If both species of Modiolicola are found, then, the origin will be from both Europe and America. However, this conclusion has to be awaited until an extensive survey of the parasite fauna of Japanese marine mussels is completed.

\section{Acknowledgements}

Examination of the mussels were made possible through the courtesy of Dr. Yoshiharu Honma and his staffs at Sado Marine Biological Station of Niigata University, Tassha, Sado Island; Dr. Saburo Isaka and his staffs at Noto Marine Laboratory of Kanazawa University, Ogi, Ishikawa Prefecture; and Dr. Eiji Harada and his staffs at Seto Marine Biological Laboratory of Kyoto University, Sirahama, Wakayama Prefecture. I acknowledge with thanks their generous assistance. I wish to thank also Dr. Takeshi Kajihara at Ocean Research Institute of Tokyo University and Dr. Ren Kuwabara at Faculty of Agriculture, Tokyo University for their valuable information on the copepod parasites of blue mussels in Tokyo Bay.

Dr. Tadashige Habe of National Science Museum, Tokyo is sincerely Acknowledged for providing information on the Japanese marine mussels. I am grateful to Ms. Mary A. Gustafson for furnishing me her unpublished data on the parasites of blue mussels occurring in Long Beach Marina, Long Beach, California.

The field work of this study was made possible through an award of sabbatical leave from California State University, Long Beach, California.

\section{REFERENCES}

Avdeev, G.V., 1977. Parasitic copepods (Cyclopoida) from bivalve molluscs of the Posiet Bay (Sea of Japan). Biologiia Moria, Akad. Nauk SSSR, 2: 34-45.

Barrett, E.M., 1963. The California oyster industry. Fish Bull., Dept. Fish and Game, California, no. 123, pp. 1-103.

Bradley, W. and A.E. Siebert, Jr., 1978. Infection of Ostrea lurida and Mytilus edulis by the parasitic copepod Mytilicola orientalis in San Francisco Bay, California. The Veliger, 21(1): 131-134.

Briggs, J.C., 1974. Marine Zoogeography. McGraw Hill Book Comp., New York, pp. 1-475.

Chew, K.K., A.K. Sparks and S.C. Katkansky, 1964. First record of Mytilicola orientalis Mori in the 
California Mussel Mytilus californianus Conrad. J. Fish. Res. Bd. Canada, 21(1): 205-207.

Dethlefsen, von V., 1972. Zur Parasitologie der Miesmuschel (Mytilus edulis L., 1758). Bericht. Deutschen Wiss. Komm. Meeresf., 22(3): 344-371.

Dinamani, P. and D.B. Gordon, 1974. On the habits and nature of association of the copepod Pseudomyicola spinosus with the Rock Oyster Crassostrea glomerata in New Zealand. J. Invert. Pathol,, 24: 305-310.

Dogiel, V.A., 1961. Ecology of the parasites of fresh water fishes. In: V.A. Dogiel, G.K. Petrushevski and Y.I. Polyanski, eds. Parasitology of Fishes. Oliver and Boyd, Ltd., London, pp. 1-384. (English translation from Russian text)

Grainger, J.N.R., 1951. Notes on the biology of the copepod Mytilicola intestinalis Steuer. Parasitol., $41: 135-142$.

Grant, U.S., 1931. Catalogue of the marine Pliocene and Pleistocene Mollusca of California and adjacent regions. Mem. San Diego Soc. Nat. Hist., 1: 1-1036.

Gustafson, M.A., (in preparation). Ecological aspects of the cyclopoid copepod Pseudomyicola spinosus occurring in the Bay Mussel Mytilus edulis in Alamitos Bay, California. M.A. Thesis, California State Univ., Long Beach, California.

Habe, T., 1978. Nippon no kairui (Shells of Japan). Nat. Sci. and Mus., 45(2): 58-63.

Hepper, B.T., 1953. Artificial infection of various molluses with Mytilicola intestinalis Steuer. Nature, London, 172: 250.

Hoshina, T. and Y. Sugiura, 1954. On a parasitic Copepoda, Pseudomyicola ostreae Yamaguti, 1936, obtained from a species of bivalve, Laternula kamakurana Pilsbry. Bull. Japanese Soc. Sci. Fish., 20(1): 13-15.

Humes, A.G., 1954. Tisbe celata n. sp., a harpacticoid copepod from the mantle cavity of the edible mussel in New Brunswick. J. Fish. Res. Bd. Canada, 11: 816-826.

- 1968. The cyclopoid copepod Pseudomyicola sprnosus (Raffael \& Monticelli) from marine pelecypods, chiefly in Bermuda and the West Indies. Beaufortia, 14(178): 203-226.

Humes, A.G. and J.H. Stock, 1973. A revision of the family Lichomolgidae Kossmann, 1877, cyclopoid copepods mainly associated with marine invertebrates. Smithsonian Contr. Zool., 127: 1-368.

Izawa, K., 1976. Two semi-parasitic copepods of marine invertebrates from Japan (Cyclopoida: Lichomolgidae). Publ. Seto Mar. Biol. Lab., 23(1/2): 89-98.

Ko, Y., Y. Murakami and K. Daiku, 1962. The biology of the commensal copepods in Japanese marine bivalves. Rec. Oceanogr. Works in Japan, Special no. 6, pp. 113-119.

Korringa, P., 1953. Epidemiological observations on the mussel parasite Mytilicola intestinalis Steuer, carried out in the Netherland 1952. Annls. Biol., Copenhagen, 9: 219-224.

Mantor, W.W., 1967. Some aspects of the geographical distribution of parasites. J. Parasitol., 53 (1): 3-9.

Monod, T. and R.P. Dollfus, 1932. Les Copépodes parasites de mollusques. Annls. Parasit, 10: 129-204.

Mori, T., 1935. Mytilicola orientalis, a new species of parasitic Copepoda. Zool. Mag., Tokyo, 47: 687-693.

Odlaug, T.O., 1946. The effect of the copepod, Mytilicola orientalis, upon the Olympia Oyster, Ostrea lurida. Trans. Am. Microsc. Soc., 65: 311-317.

Soot-Ryen, T., 1955. A report on the family Mytilidae (Pelecypoda). Allan Hancock Pacific Exped., 20: $1-176$.

Steuer, A., 1903. Mytilicola intestinalis n. gen. n. sp. Arb. Zool. Inst. Univ. Wien, 15: 1-46.

Stock, J.H., 1960. Sur qulques copépodes associés aux invertebres des côtes du Roussilion. Crustaceana, $1(3): 218-257$.

Tanaka, O., 1961. On copepods associated with marine pelecypods in Kyushu. J. Fac. Agr., Kyushu Univ., $11(3): 249-273$.

Williams, C.S., 1969. The life history of Mytilicola intestinalis Steuer. J. Cns. Int. Explor. Mer., 32(3): $419-428$.

Wilson, C.B., 1938. A new copepod from Japanese oyster transplanted to the Pacific coast of the United States. J. Wash. Acad. Sci., 28: 284-288.

Yamaguti, S., 1936. Parasitic copepods from mollusks of Japan, I. Japanese J. of Zool., 7(1): 113-127 